\title{
Identification of Potential Peroxisomal Proteins in Mouse
}

Igor V. Kurochkin, ${ }^{1,6}$ RIKEN GER Group ${ }^{2}$ and GSL Members, ${ }^{3,5}$ Akihiko Konagaya, ${ }^{1,4}$ Takeshi Nagashima, ${ }^{1,4}$ and Christian Schönbach ${ }^{1,6}$

${ }^{1}$ Biomedical Knowledge Discovery Team, Bioinformatics Group, RIKEN Genomic Sciences Center, Yokohama 230-0045, Japan; ${ }^{2}$ Laboratory for Genome Exploration Research Group, RIKEN Genomic Sciences Center (GSC), RIKEN Yokohama Institute, Suehiro-cho, Tsurumi-ku, Yokohama, Kanagawa 230-0045, Japan; ${ }^{3}$ Genome Science Laboratory, RIKEN, Hirosawa, Wako, Saitama 351-0198, Japan; ${ }^{4}$ Department of Knowledge System Science, School of Knowledge Science, Advanced Institute of Science and Technology, Ishikawa, 923-1292, Japan

Peroxisomes, small vesicle-like subcellular respiratory organelles present in all eukaryotic cells, play a critical role in $\beta$-oxidation of fatty acids, glyoxylate metabolism, gluconeogenesis, and sterol biosynthetic pathway. The importance of peroxisomes for humans is stressed by the existence of a group of serious metabolic disorders caused either by impairment of peroxisome biogenesis or by defects of individual peroxisomal enzymes. Detailed cataloging of peroxisome proteins, "the peroxiproteome", will significantly impact our understanding of peroxisome biology and aid in discovery of molecular targets to treat disorders associated with this organelle.

First, we analyzed the FANTOM2 cDNA collection for the presence of peroxins (Pex), the proteins that are essential for peroxisome biogenesis. So far, 24 PEX genes have been characterized in yeast. Of these, BLAST analysis of FANTOM2 RTPS revealed 13 PEX genes conserved in mouse (PEX1, PEX2, PEX3, PEX5, PEX6, PEX7, PEX10, PEX11, PEX12, PEX13, PEX14, PEX16, and PEX19). By comparison with the human, the coverage of PEX proteins in the mouse FANTOM2 set is complete, as human homologs have been found so far for the same set of 13 PEX genes.

Second, to identify new peroxisomal proteins, we searched RTPS for ORFs that contain the carboxy-terminal peroxisome-targeting signal S/AKL (PTS1). In addition to 23 previously known PTS1-containing peroxisomal proteins, this analysis identified 5 putative new proteins that could be targeted to the organelles. Analysis of the candidate protein sequences for known motifs suggests that at least two of the proteins might perform catalytic functions. One of them (FANTOM2 clone ID of representative transcript is C530046K17; additional information for clones is available through the FANTOM2 Web site: http://fantom2.gsc.riken.go.jp/db/ annotate/main.cgi?masterid=CLONE_ID) encodes a novel member of the zinc-containing alcohol dehydrogenase superfamily of proteins. It contains NAD(P)-binding Rossmann-fold domains and is weakly similar to Arabidopsis thaliana probable NADP-dependent oxidoreductases. No mammalian homologs for this protein have been reported so far, and thus, it may represent a novel peroxisomal enzyme. Another clone (1300019N10) predicts a protein containing Serine protease domain. So far, only one protease, insulin-degrading enzyme, has been shown to be present in peroxisomes. The remaining five clones encode proteins with no significant homology to other proteins and lacking any known motifs, for example, a hypothetical protein of 114 amino acids (9530079E12), hypothetical protein of 103 amino acids (D130032)17), and a protein weakly similar to human HT021 protein (3830406C13). Further experiments have to determine whether candidate peroxisome proteins identified here are actually localized to peroxisomes, and if so, elucidate their role in these organelles.

\footnotetext{
${ }_{6}^{5}$ Takahiro Arakawa, ${ }^{2}$ Piero Carninci, ${ }^{2,3}$ Jun Kawai, ${ }^{2,3}$ and Yoshihide Hayashizaki ${ }^{2,3}$

${ }^{6}$ Corresponding authors.

E-MAIL igork@gsc.riken.go.jp; FAX 045-503-9552.

E-MAIL schoen@gsc.riken.go.jp; FAX 045-503-9552.

Article and publication are at http://www.genome.org/cgi/doi/10.1101/gr.1456303.
} 


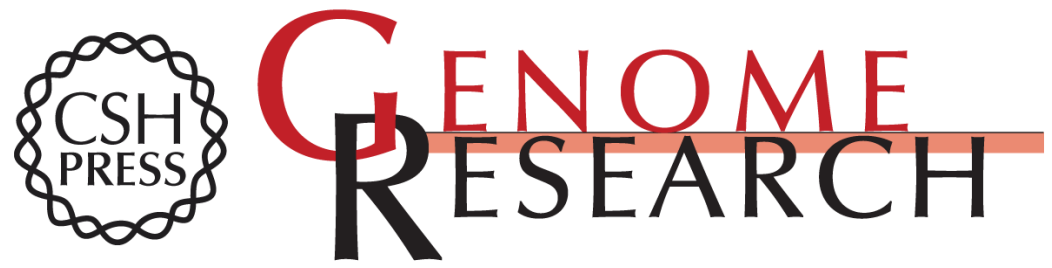

\section{Identification of Potential Peroxisomal Proteins in Mouse}

Igor V. Kurochkin, RIKEN GER Group, GSL Members, et al.

Genome Res. 2003 13: 1560

Access the most recent version at doi:10.1101/gr.1456303

\section{License}

Email Alerting Receive free email alerts when new articles cite this article - sign up in the box at the Service top right corner of the article or click here.

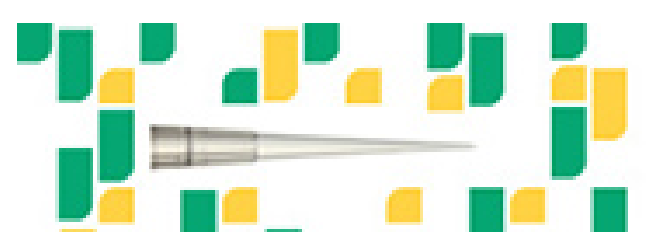

To subscribe to Genome Research go to: https://genome.cshlp.org/subscriptions 